\title{
Characterization of Neuraminidase Inhibitors in Korean Papaver rhoeas Bee Pollen Contributing to Anti-Influenza Activities In Vitro
}

Authors

Affiliations

In-Kyoung Lee ${ }^{1 *}$, Byung Soon Hwang ${ }^{1 *}$, Dae-Won Kim ${ }^{1}$, Ji-Yul Kim ${ }^{1}$, E-Eum Woo ${ }^{1}$, Yoon-Ju Lee ${ }^{1}$, Hwa Jung Choi ${ }^{2}$, Bong-Sik Yun ${ }^{1}$

\footnotetext{
${ }^{1}$ Division of Biotechnology and Advanced Institute of Environment and Bioscience, Chonbuk National University, Iksan-si, Republic of Korea

2 Department of Beauty Science, Kwangju Women's University, Sanjeong-dong, Gwangsan-gu, Kwangju, Republic of Korea
}

\author{
Key words \\ - Papaver rhoeas \\ - Papaveraceae \\ - bee pollen \\ - Apis mellifera \\ - neuraminidase inhibitors \\ - anti-influenza activity \\ - flavonoid glycosides
}

\section{Abstract \\ $\nabla$}

The active constituents of Korean Papaver rhoeas bee pollen conferring neuraminidase inhibitory activities (H1N1, H3N2, and H5N1) were investigated. Six flavonoids and one alkaloid were isolated and characterized by nuclear magnetic resonance and mass spectrometry data. These included kaempferol-3-sophoroside (1), kaempferol-3-neohesperidoside (2), kaempferol-3-sambubioside (3), kaempferol-3-glucoside (4), quercetin-3-sophoroside (5), luteolin (6), and chelianthifoline (7). All compounds showed neuraminidase inhibitory activities with $\mathrm{IC}_{50}$ values ranging from 10.7 to $151.1 \mu \mathrm{M}$. The most potent neuraminidase inhibitor was luteolin, which was the dominant content in the ethyl acetate fraction. All tested compounds displayed noncompetitive inhibition of H3N2 neuraminidase. Furthermore, compounds 1-7 all reduced the severity of virally induced cytopathic effects as determined by the Madin-Darby canine kidney cell-based assay showing antiviral activity with $\mathrm{IC}_{50}$ values ranging from 10.7 to $33.4 \mu \mathrm{M}$ (zanamivir: $58.3 \mu \mathrm{M}$ ). The active compounds were quantified by high-

\section{Introduction}

$\nabla$

2016

Planta Med 2016; 82: 524-529

(c) Georg Thieme Verlag KG

Stuttgart · New York .

ISSN 0032-0943

\section{Correspondence}

Bong-Sik Yun

Division of Biotechnology and Advanced Institute of

Environment and Bioscience

Chonbuk National University

79 Gobong-ro

Iksan-si 570-752

Republic of Korea

Phone: + 82638600839

Fax: +82638600834

bsyun@jbnu.ac.kr
Bee pollen is a granule-type material of agglutinated flower pollen made by worker honey bees with nectar and bee secretions. The resulting pollen is higher in nutritional value than untreated pollen, and is used as the primary source of protein for the bee hive. Bee pollen has been used in folk medicine from ancient times in many regions of the world for its medical properties to alleviate or cure conditions such as colds, flu, ulcers, and anemia [1]. Recently, biological effects such as antiox-

\footnotetext{
* In-Kyoung Lee and Byung Soon Hwang contributed
} equally to this work. performance liquid chromatography, and the total amount of compounds 1-7 made up about $0.592 \mathrm{~g} / 100 \mathrm{~g}$ bee pollen, contributing a rich resource of a natural antiviral product.

\section{Abbreviations \\ $\nabla$ \\ CPE: $\quad$ cytopathic effect \\ EDTA: ethylenediaminetetraacetic acid \\ HPLC: high-performance liquid \\ chromatography \\ HA: hemagglutinin \\ MDCK: Madin-Darby canine kidney \\ MS: $\quad$ mass \\ NA: neuraminidase \\ NAI: neuraminidase inhibitors \\ NMR: nuclear magnetic resonance \\ ODS: octadecyl silica \\ SRB: $\quad$ Sulforhodamine B \\ TFA: trifluoroacetic acid \\ TI: $\quad$ therapeutic index}

Supporting information available online at http://www.thieme-connect.de/products

idation [2], anti-inflammation [3], antiallergy [4], antifungal [5], anticancer [6], chemopreventive [7], and antimutagenic [8] activities were also reported.

Like other apicultural products, royal jelly, honey, and propolis, the chemical composition of bee pollen depends on the plant source, regional vegetation, season, and honeybee races at the site of collection. It is rich in carbohydrates, proteins, lipids, minerals, vitamins, and various organic compounds, including phenolic acids and flavonoids. Most flavonoids from bee pollen exist as glycosides and contain kaempferol or quercetin as aglycone parts. Other phenolic acids usually found in 


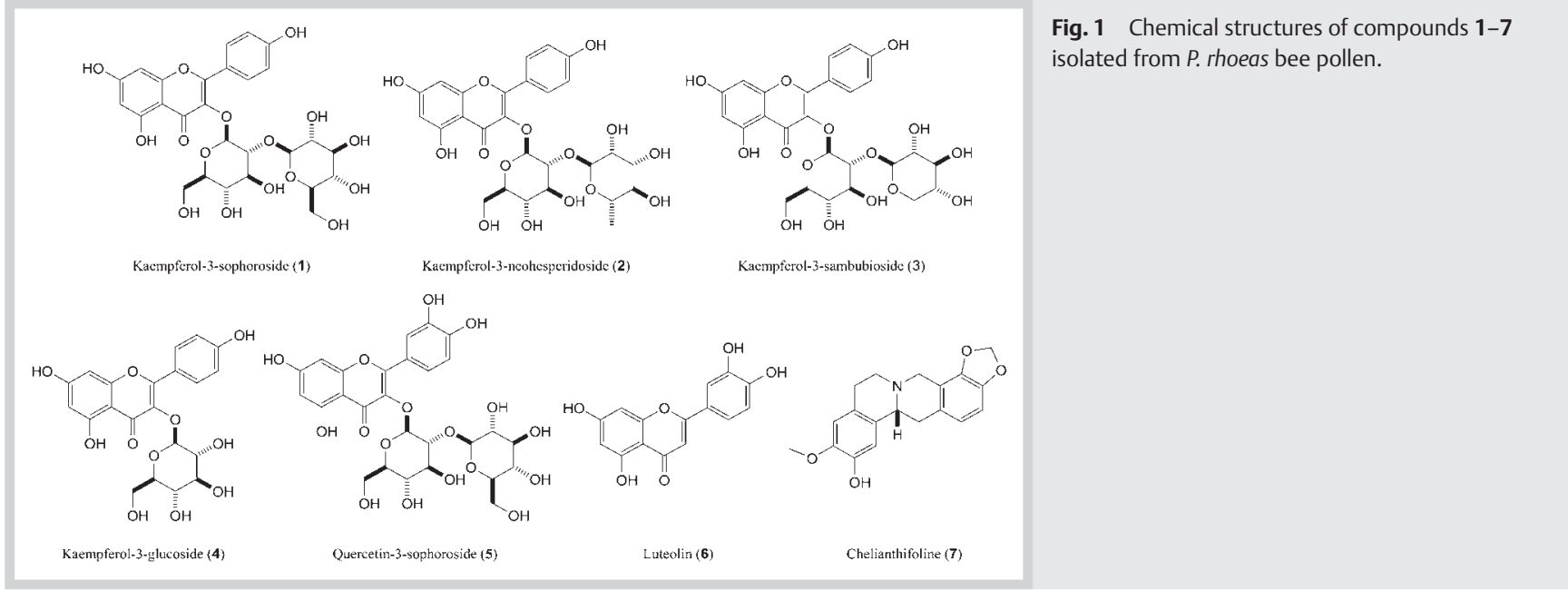

floral parts, such as triacylated spermidine, were identified as major constituents of bee pollen [9].

Influenza viruses contain two surface antigens, NA and HA. NA and HA both recognize carbohydrate structures and bind to terminal sialic acid units on the surface of the host cell. When the influenza virus replicates, the binding of HA to its receptor initiates viral entry into the host cell, where NA catalyzes the cleavage of sialic acid. Since NA plays an important role in replication, spread, and pathogenesis during infection, blocking the function of NA is considered to be one of the most promising areas of targeting for the treatment of influenza. In the past decade, many reports have investigated substances related to NA inhibition. It was previously reported that flavonoids and (oligo) stilbenes are the most prominent natural products with NA inhibitory activity [10]. Therefore, pollen is considered one of the natural sources of NA inhibitors due to its high levels of polyphenols.

Papaver rhoeas $\mathrm{L}$. is a species of flowering plant in the poppy family, Papaveraceae. It is sometimes mistaken for Papaver somniferum L., the opium poppy. It was reported that the flavonoids kaempferol, quercetin, luteolin, 8-hydroxyluteolin (hypolaetin), quercetin-3-glucoside (isoquercitrine), kaempferol-3-glucoside (astragaline), and quercetin-3-galactoside (hyperoside) were isolated from the methanol extract of the petals of Papaver rhoeas [11].

Although pollen has traditionally been used to treat the cold and flu, there are no reports of the antiviral activities of $P$. rhoeas bee pollen. In the present study, we investigated the active agents of Korean $P$. rhoeas bee pollen for inhibitory activity on NA from influenza virus A H1N1, H3N2, and H5N1, with an investigation of the anti-influenza viral activities in MDCK cells through a CPE reduction assay.

\section{Results and Discussion}

Influenza NA has been established as a primary drug target for the treatment of influenza infections. Cell culture-based assays need to be performed to evaluate the cytotoxicity and to confirm the anti-influenza activity of potential NAIs. Therefore, we first investigated the active constituents of Korean $P$. rhoeas bee pollen on NA inhibition. The neuraminidase inhibitors, compounds 1-7, from the ethyl acetate fraction of $P$. rhoeas bee pollen were isolated by chromatographic procedures, including purification via silica gel, Sephadex LH-20, ODS Sepak cartridges, and HPLC. The isolated compounds were identified as six flavonoids and one alkaloid by NMR and MS spectral data (see Supporting Information for details): kaempferol-3-sophoroside (kaempferol3-0- $\beta$-D-glucosyl $(1 \rightarrow 2)-\beta$-D-glucoside) (1), kaempferol-3-neohesperidoside (kaempferol-3-O- $\beta$-D-rhamnosyl $(1 \rightarrow 2)-\beta$-D-glucoside) (2), kaempferol-3-sambubioside (kaempferol-3-O- $\beta$-Dxylosyl $(1 \rightarrow 2)-\beta$-D-glucoside) (3), kaempferol-3-O- $\beta$-D-glucoside (4), quercetin-3-sophoroside (quercetin-3-0- $\beta$-D-glucosyl $(1 \rightarrow 2)-\beta$-D-glucoside) (5), luteolin (6), and chelianthifoline (7), as shown in $\odot$ Fig. 1. Particularly, the glycoside part of the flavonoids isolated from $P$. rhoeas bee pollen was substituted on position 3 of the aglycone for kaempferol and quercetin. Compounds $\mathbf{1}, \mathbf{2}, \mathbf{3}$, and $\mathbf{5}$ had a common $1 \rightarrow 2$ linkage between biglycosides, which was established by HMBC spectral data. Compound 7 was previously reported as an active ingredient of Corydalis impatiens (Pall.) Fisch. ex DC. (Papaveraceae) [12] and as one of the urinary metabolites of protopine alkaloids unique to Papaver spp. [13].

The NA inhibitory activities of compounds 1-7 were evaluated against the recombinant influenza viral subtypes H1N1, H3N2, and H5N1, with zanamivir as a positive control. All compounds displayed inhibition of NAs in a dose-dependent manner. The $\mathrm{IC}_{50}$ values of compounds $\mathbf{1 - 7}$ on the NAs from influenza H1N1, H3N2, and H5N1 ranged from 10.7 to $100.5,25.6$ to 143.2 , and 12.6 to $151.1 \mu \mathrm{M}$, respectively ( Table 1 ). Compound 6, luteolin, exhibited the highest activity against the NAs of all three types. Comparison of the flavonoid glycosides (1-5) with the aglycone (6) indicated that the bulky sugar moiety in compounds 1-5 caused a loss of activity. However, compound $\mathbf{7}$ (chelianthifoline), an alkaloid, exhibited weak activity.

The manner of inhibition by the compounds was determined to evaluate the relative affinity for NA from the H3N2 influenza virus. To study the mode of inhibition, Dixon plots were used. As shown in Fig. 2, all compounds tested (compounds 1-4, 6, and 7) displayed noncompetitive inhibitory activity, because the $V_{\max }$ decreased while the $\mathrm{K}_{\mathrm{m}}$ remained the same with increasing concentrations of inhibitors, which intersected at a non-zero point on the $\mathrm{x}$ axis $\left(\mathrm{K}_{\mathrm{i}}\right)$. The $\mathrm{K}_{\mathrm{i}}$ values for these compounds were similar to their $\mathrm{IC}_{50}$ values ( $\odot$ Table $\mathbf{1}$ ). To date, all flavonoids tested were reported to act noncompetitively. Recently, it was reported that essential functional groups of flavonoids to confer good NA inhibitory effects are hydroxyl groups in positions $4^{\prime}$ and 7 , an oxo 
Table 1 Inhibitory effect of compounds 1-7 on neuraminidase activities and antiviral activity against influenza A virus in MDCK cells.

\begin{tabular}{|c|c|c|c|c|c|c|c|}
\hline \multirow{2}{*}{$\begin{array}{l}\text { Com- } \\
\text { pounds }\end{array}$} & \multicolumn{3}{|c|}{ NA inhibition $\mathrm{IC}_{50}(\mu \mathrm{M})$} & \multirow{2}{*}{$\begin{array}{l}\text { Inhibition type } \\
\left(\mathbf{k}_{\mathrm{i}}, \mu \mathrm{M}\right)\end{array}$} & \multicolumn{3}{|c|}{ Cytotoxicity and antiviral activity ( $\mu \mathrm{M})$} \\
\hline & H1N1 & H5N1 & H3N2 & & $\mathrm{CC}_{50} \mathrm{a}^{\mathrm{a}}$ & $\mathrm{IC}_{50}^{\mathrm{b}}$ & $\mathrm{TI}^{\mathrm{C}}$ \\
\hline 1 & $85.6 \pm 1.4$ & $111.6 \pm 1.0$ & $61.0 \pm 0.7$ & $\begin{array}{l}\text { Noncompetitive } \\
(90.0 \pm 1.9)\end{array}$ & $>100$ & $21.3 \pm 1.2$ & $>4.7$ \\
\hline 2 & $56.2 \pm 1.1$ & $80.2 \pm 4.8$ & $51.6 \pm 1.5$ & $\begin{array}{l}\text { Noncompetitive } \\
(57.8 \pm 1.6)\end{array}$ & $>100$ & $12.8 \pm 4.2$ & $>7.8$ \\
\hline 3 & $45.3 \pm 1.9$ & $51.2 \pm 3.1$ & $52.2 \pm 2.9$ & $\begin{array}{l}\text { Noncompetitive } \\
(61.2 \pm 0.7)\end{array}$ & $>100$ & $33.4 \pm 2.4$ & $>3.0$ \\
\hline 4 & $36.3 \pm 1.5$ & $61.1 \pm 2.1$ & $54.0 \pm 1.2$ & $\begin{array}{l}\text { Noncompetitive } \\
(56.7 \pm 1.3)\end{array}$ & $>100$ & $15.7 \pm 4.2$ & $>6.4$ \\
\hline 5 & $88.3 \pm 3.0$ & $75.1 \pm 8.7$ & $112.8 \pm 8.2$ & $N D^{\mathrm{e}}$ & $>100$ & $12.5 \pm 3.2$ & $>8.0$ \\
\hline 6 & $10.7 \pm 0.2$ & $12.6 \pm 0.8$ & $25.6 \pm 8.3$ & $\begin{array}{l}\text { Noncompetitive } \\
(46.1 \pm 2.3)\end{array}$ & $>100$ & $10.7 \pm 1.6$ & $>9.4$ \\
\hline 7 & $100.5 \pm 9.2$ & $151.1 \pm 19.8$ & $143.2 \pm 8.9$ & $\begin{array}{l}\text { Noncompetitive } \\
(132.2 \pm 0.7)\end{array}$ & $>100$ & $21.5 \pm 6.2$ & $>4.7$ \\
\hline Zanamivir $^{d}$ & $1.5 \pm 0.2 \mathrm{nM}$ & $3.4 \pm 0.1 \mathrm{nM}$ & $1.9 \pm 0.4 \mathrm{nM}$ & ND & $>100$ & $58.3 \pm 1.6$ & $>1.7$ \\
\hline
\end{tabular}

Results were obtained from three independent experiments carried out in triplicate, and are expressed as the mean \pm S. D.; ${ }^{\text {a }}$ Concentration required to reduce cell growth by $50 \%$; ${ }^{\mathrm{b}}$ concentration required to inhibit virus-induced $\mathrm{CPE}$ by $50 \%$; ${ }^{\mathrm{c}}$ therapeutic index $=\mathrm{CC}_{50} / \mathrm{IC}_{50}$; ${ }^{\mathrm{d}}$ the compound used as the positive control; ${ }^{\mathrm{e}}$ not determined

group in position 4, and a double bond between positions 2 and 3, showing agreement with our results [4].

The antiviral activities of compounds 1-7 against the influenza $A$ virus were determined using the CPE reduction assay in MDCK cells to evaluate the cytotoxicity and to confirm the anti-influenza activity ( Table 1). The $\mathrm{IC}_{50}$ values of these compounds were 10.7-33.4 $\mu \mathrm{M}$, and the TI values were 2.99-9.35, which was 1.7to 5.5-fold higher than that of zanamivir ( $\mathrm{IC}_{50}: 58.3 \mu \mathrm{M}$, TI: 1.7 ). Luteolin (6) was the most effective with an $\mathrm{IC}_{50}$ value of $10.7 \mu \mathrm{M}$ (TI: > 9.35). Interestingly, alkaloid compound 7 demonstrated more potent activity in the CPE reduction assay than in the measurement of the neuraminidase inhibition effect. All of the compounds tested were not toxic to MDCK cells, displaying 100\% viability at the concentration of $100 \mu \mathrm{M}$ ( Table 1 ).

After 2 days of infection of MDCK cells with the influenza A virus, no differences were observed between the mock cells (non-virulent cells, Fig. 3) and those treated with $10 \mu \mathrm{M}$ of the compounds (data not shown) in terms of normal morphology, with typical spread-out shapes. As shown in $\odot$ Fig. 3, severe CPE was observed in influenza A virus-infected cells that were not treated with any of the compounds or with zanamivir. Compounds 2, 4, 5, and 6 potently inhibited the virus-induced CPE in infected MDCK cells ( Fig. 3). Compounds 1 and 7 displayed moderate antiviral activities, while 3 only weakly reduced the CPE; however, their activities were comparable to that of zanamivir.

The qualification of the methanol extract and ethyl acetate fraction of bee pollen was performed by HPLC analysis on the basis of the retention time of the pure compounds and UV spectral data (- Fig. 4). Compounds 1-3 and 6 (peaks 1-3 and 6) were dominant constituents in the ethyl acetate fraction, making up 55\% from the HPLC analysis data. Comparison of the two HPLC profiles revealed distinct differences in the peak of compound 6 . Therefore, these results were consistent with the high neuraminidase inhibition shown by the ethyl acetate fraction of bee pollen. Peaks 8-10 were shown as main constituents (19\% from HPLC analysis of ethyl acetate fraction), but demonstrated no neuraminidase inhibitory activity up to $200 \mu \mathrm{M}$. The quantitative amount of compounds 1-7 found in the methanol extract of bee pollen is shown in Table 2. Calibration curves for compounds 1-7 were linear, as evidenced by the correlation coefficients $\left(r^{2}=0.997-0.999\right)$. The content of 1 was the highest (about $0.3 \%$ of the total amount), while $\mathbf{2}$ and $\mathbf{5}$ were the major components, amounting to about $0.22 \%$ of the total amount. Compounds 3, 6, and 7 were detected in small quantities, while 4 was not detected, as it was below $0.001 \%$. The total amount of active ingredients (1-7) of $P$. rhoeas bee pollen was about $0.592 \mathrm{~g} / 100 \mathrm{~g}$ (dry bee pollen), which was considered to contribute as a rich resource of a natural antiviral product. The qualitative and quantitative analyses were carried out in triplicate with different batches and were reproducible.

Bee pollens have different chemical compositions depending on the plant source, regional vegetation, season, and honeybee races at the site of collection, and consequently, the biological activities of the bee pollens were different. Korean $P$. rhoeas bee pollen consisted of diverse flavonoid glycosides of high content exhibiting potent neuraminidase inhibition activity. Although these compounds were less active than zanamivir, a commercially available NA inhibitor, in our enzyme assay, they were more effective than zanamivir in the $\mathrm{CPE}$ reduction assay. This phenomenon suggests that the compounds isolated may have another mechanism of action in addition to neuraminidase inhibition. The detailed mechanism of action of these compounds still remains to be investigated. Importantly, this is the first report of the antiviral activity of $P$. rhoeas bee pollen, including NA inhibition and CPE reduction effects in influenza virus A-infected MDCK cells. Taken together, $P$. rhoeas bee pollen and its extract are good candidates for the development of novel prophylactic and therapeutic strategies against viral infection.

\section{Materials and Methods}

$\nabla$

\section{Pollen material}

P. rhoeas bee pollen was provided and authenticated by emeritus professor Kwang-Ryul Choe at Chungnam National University, Daejeon, Korea, in 2011. P. rhoeas bee pollen was collected by honey bees, Apis mellifera L., at Chungnam province, Korea, in May-July 2011. A voucher specimen (Y-2011-01) was deposited at the herbarium of Chonbuk National University, Jeonbuk, Korea. 


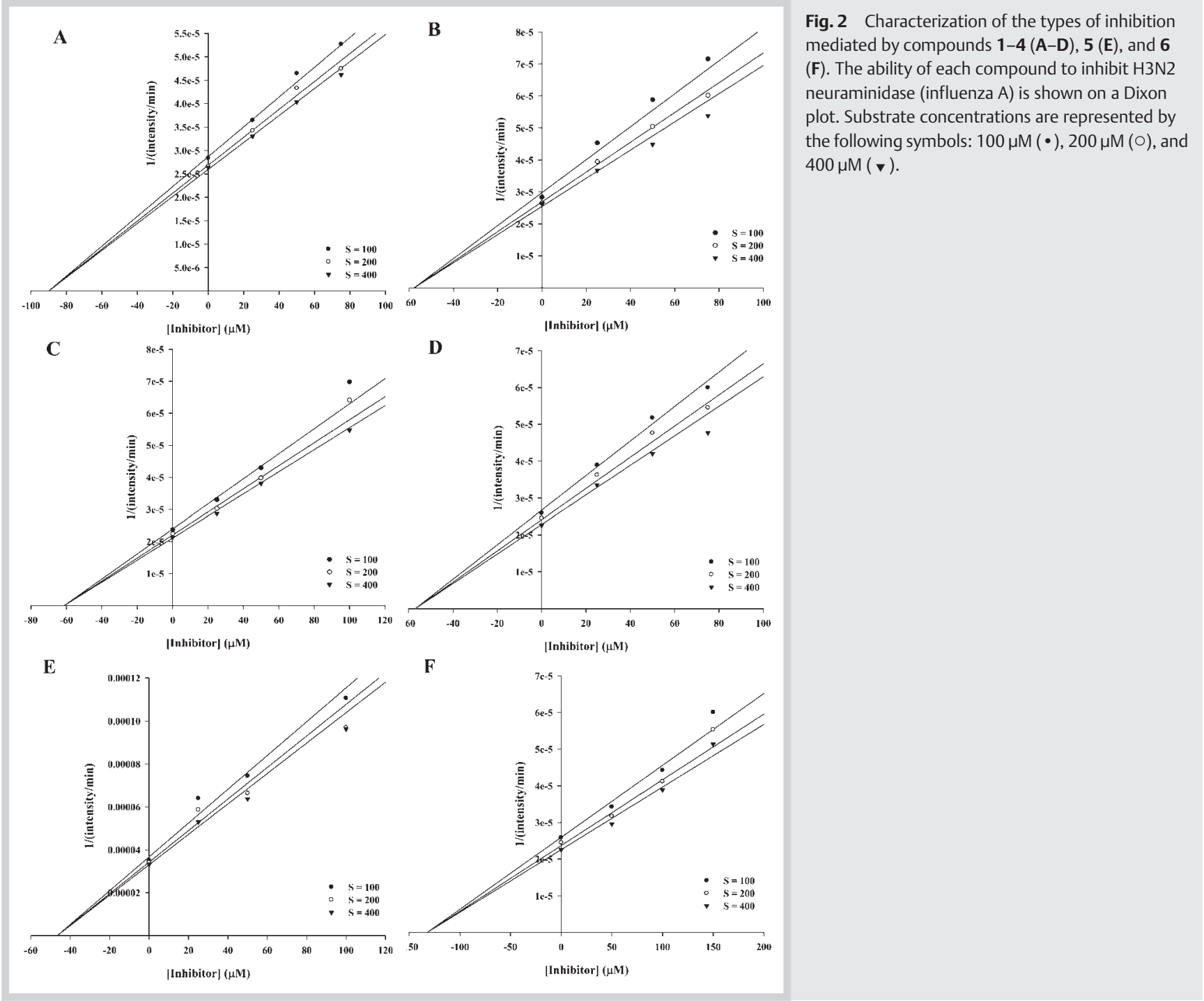

High-performance liquid chromatography analysis The qualitative and quantitative analyses of the methanol extract of $P$. rhoeas bee pollen were characterized by the HPLC photo-diode array detection (PDA) system. For qualitative analysis, samples $(10 \mu \mathrm{L})$ were injected into an analytical ODS column. The mobile phase was composed of $0.04 \%$ trifluoro acetic acid in water (A) and methanol (B). The gradient conditions were as follows: 3 min, 20\% B; 35 min, 50\% B; 40 min, 50\% B, with a flow rate of $1 \mathrm{~mL} / \mathrm{min}$ and the detection at $207 \mathrm{~nm}$. For quantitative analysis, the standard curves of compounds $1-7$ were prepared over a concentration range of $31.25-250 \mu \mathrm{g} / \mathrm{mL}$ with four different concentration levels. Samples $(15 \mu \mathrm{L})$ were injected into an analytical ODS column. The mobile phases and detection conditions were as follows: $20 \%$ aqueous methanol (0.04\% TFA) for $\mathbf{1}$, 5, and 7, 25\% aqueous methanol (0.04\% TFA) for $\mathbf{2}$ and 3, 30\% aqueous methanol ( $0.04 \% \mathrm{TFA}$ ) for 4 , and $40 \%$ aqueous methanol $(0.04 \%$ TFA) for 6 . The detection wavelengths were $286 \mathrm{~nm}$ for 7 , $254 \mathrm{~nm}$ for $\mathbf{5}, 264 \mathrm{~nm}$ for $\mathbf{1 - 4}$, and $349 \mathrm{~nm}$ for $\mathbf{6}$. A line for each compound was plotted using linear regression of the peak area vs. concentration. The coefficient of correlation $\left(\mathrm{r}^{2}\right)$ was used to judge the linearity.

\section{Extraction and isolation}

The dried pollen $(400 \mathrm{~g})$ was extracted with $70 \%$ methanol $(1 \mathrm{~L} \times 3)$ for $24 \mathrm{~h}$ at room temperature, and the solution was concentrated under reduced pressure to obtain a crude extract $(150 \mathrm{~g})$. The extract was partitioned successively with $n$-hexane, chloroform, ethyl acetate, and butanol. The ethyl acetate fraction exhibited the most potent inhibitory activity against H1N1 neuraminidase. Therefore, the ethyl acetate fraction $(3 \mathrm{~g})$ was then subjected to a $\mathrm{C}_{18}$ Sepak cartridge eluting with a gradient of increasing methanol (10-100\%) in water to give four fractions (Fr. I-IV) based on the silica TLC pattern and HPLC analysis. Fractions I and II were followed by reversed-phase preparative HPLC with $35 \%$ aqueous $\mathrm{MeOH}(0.04 \%$ TFA) and $40 \%$ aqueous $\mathrm{MeOH}(0.04 \%$ TFA), respectively, at a flow rate of $6 \mathrm{~mL} / \mathrm{min}$. Compounds 1 ( $t_{R}$ $34 \mathrm{~min}, 33.2 \mathrm{mg}$ ), 2 ( $t_{\mathrm{R}} 44 \mathrm{~min}, 35.5 \mathrm{mg}$ ), 5 ( $t_{\mathrm{R}} 22 \mathrm{~min}, 13.7 \mathrm{mg}$ ), and $\mathbf{3}\left(t_{\mathrm{R}} 60 \mathrm{~min}, 26.1 \mathrm{mg}\right)$ were isolated from fraction I, while $\mathbf{4}$ ( $t_{\mathrm{R}} 79 \mathrm{~min}, 22.3 \mathrm{mg}$ ) was obtained from fraction II. Fraction III was chromatographed on a Sephadex LH-20 column with $\mathrm{MeOH}$, and then purified by reversed-phase preparative HPLC with a $50 \sim 80 \%$ aqueous $\mathrm{MeOH}$ gradient $(0.04 \% \mathrm{TFA})$ at a flow rate of $8 \mathrm{~mL} / \mathrm{min}$ to yield 7 ( $\left.t_{\mathrm{R}} 26 \mathrm{~min}, 9 \mathrm{mg}\right)$. Compound 6 (14.2 mg) was obtained by column chromatography of a silica gel eluted 


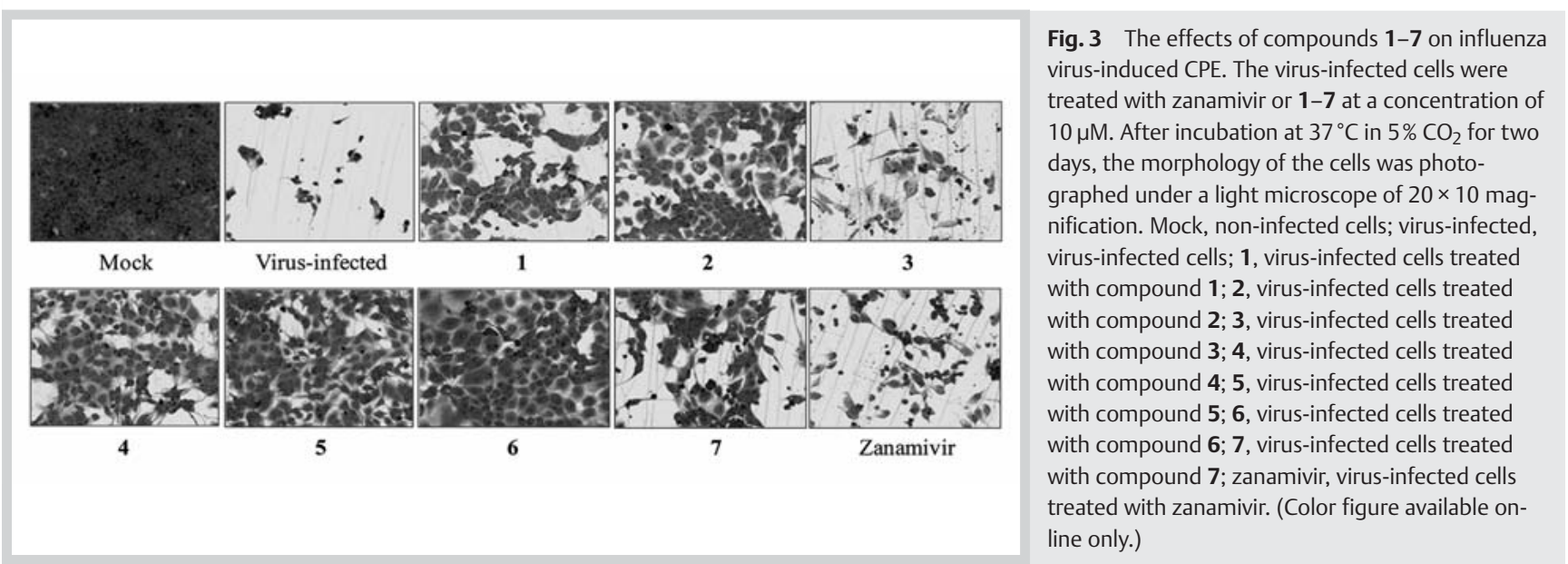

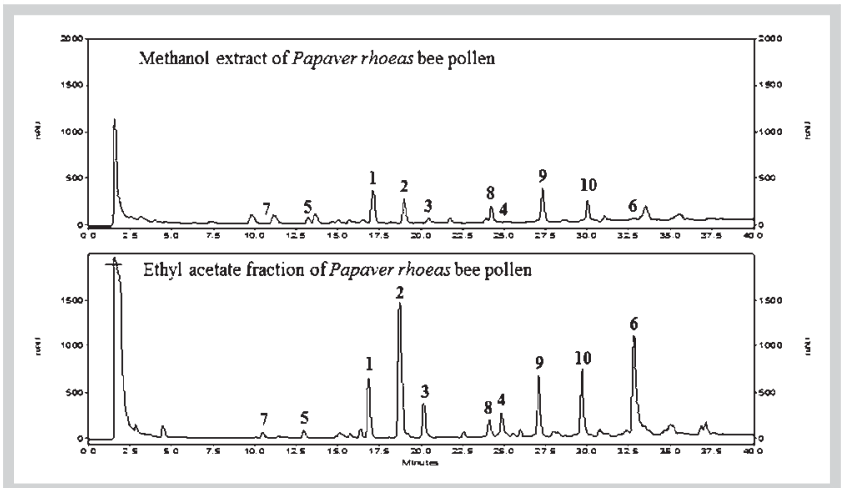

Fig. 4 Representative HPLC profiles of the methanol extract and ethyl acetate fraction of $P$. rhoeas bee pollen. HPLC was performed with a TSK-GEL ODS- $100 \mathrm{~V}$ column $(4.6 \times 150 \mathrm{~mm}$, TOSHO, Japan) at $207 \mathrm{~nm}$ with a flow rate of $1 \mathrm{~mL} / \mathrm{min}$. Peak identity: kaempferol-3-sophoroside (1), kaempferol-3-neohesperidoside (2), kaempferol-3-sambubioside (3), kaempferol-3-glucoside (4), quercetin-3-sophoroside (5), luteolin (6), chelianthifoline (7), not identified (8-10).

with $\mathrm{CHCl}_{3}-\mathrm{MeOH}(10: 1)$ and a Sephadex $\mathrm{LH}-20$ eluted with $\mathrm{CHCl}_{3}: \mathrm{MeOH}(1: 1)$ from fraction IV.

\section{Neuraminidase inhibitory activity}

Neuraminidase inhibitory activity was estimated using a previously reported fluorometric (FL) method, with some modifications [14]. Recombinant influenza A virus H1N1, H3N2, and H5N1 NAs were purchased from R \& D systems. The substrate for the $\mathrm{FL}$ assays, 4-methylumbelliferyl-N-acetyl- $\alpha$-D-neuraminic acid (MUNANA), is cleaved by NA to release N-acetyl- $\alpha$-Dneuraminic acid (NANA) and the fluorescent compound 4-methylumbelliferone (MU). Therefore, NA inhibition by an NA inhibitor causes a reduced fluorescence of the MU. The substrate, $50 \mu \mathrm{L}$ of $0.2 \mathrm{mM}$ MUNANA, was mixed with $90 \mu \mathrm{L}$ of $50 \mathrm{mM}$ Tris buffer (containing $200 \mathrm{mM} \mathrm{NaCl}, 5 \mathrm{mM} \mathrm{CaCl}_{2}, \mathrm{pH} 7.5$ ) at room temperature. Ten microliters of the sample and $50 \mu \mathrm{L}$ of H1N1 NA $(50 \mathrm{ng} / \mathrm{mL})$ were added to a well in a plate. The mixture was then recorded at the excitation and emission wavelengths of $365 \mathrm{~nm}$ and $445 \mathrm{~nm}$, respectively, with a POLAR OPTIMA. In the case of H3N2 and H5N1 NAs, 25 mM MES buffer (containing $500 \mathrm{mM} \mathrm{NaCl}, 5 \mathrm{mM} \mathrm{CaCl}_{2}$, pH 6.5) and $50 \mathrm{mM}$ MES buffer (containing $500 \mathrm{mM} \mathrm{NaCl}, 5 \mathrm{mM} \mathrm{CaCl}_{2}$, pH6.5) were used, respective-
Table 2 Qualitative and quantitative analysis of compounds 1-7 found in the methanol extract of $P$. rhoeas bee pollen.

\begin{tabular}{|c|c|c|c|}
\hline $\begin{array}{l}\text { Peak } \\
\text { No. }\end{array}$ & $\begin{array}{l}t_{R} \\
(\min )\end{array}$ & $\begin{array}{l}\text { Dried pollen } \\
(\mathrm{mg} / 100 \mathrm{~g})^{\mathrm{a}, \mathrm{b}}\end{array}$ & Identification \\
\hline 1 & 16.8 & $294.9 \pm 4.5$ & kaempferol-3-sophoroside (1) \\
\hline 2 & 18.6 & $154.8 \pm 1.3$ & kaempferol-3-neohesperidoside (2) \\
\hline 3 & 20.1 & $24.5 \pm 1.3$ & kaempferol-3-sambubioside (3) \\
\hline 4 & 24.8 & $\mathrm{ND}^{\mathrm{C}}(<1)$ & kaempferol-3-glucoside (4) \\
\hline 5 & 12.9 & $63.2 \pm 1.0$ & quercetin-3-sophoroside (5) \\
\hline 6 & 32.7 & $24.9 \pm 0.5$ & Luteolin (6) \\
\hline 7 & 10.4 & $30.1 \pm 0.9$ & Chelianthifoline (7) \\
\hline 8 & 24.0 & $N T^{d}$ & Unknown \\
\hline 9 & 27.0 & NT & Unknown \\
\hline 10 & 29.6 & NT & Unknown \\
\hline
\end{tabular}

a Values are means $(\mathrm{n}=3)$; ${ }^{\mathrm{b}}$ standard deviation; ${ }^{\mathrm{c}}$ not detected; ${ }^{\mathrm{d}}$ not tested

ly, and $\mathrm{H} 5 \mathrm{~N} 1$ required an activation period of $24 \mathrm{~h}$ at $37^{\circ} \mathrm{C}$ before the assay. The other methods were the same as those for H1N1 NA. The $50 \%$ inhibitory concentration $\left(\mathrm{IC}_{50}\right)$ for enzymatic activity of neuraminidase was determined from the dose-response curve using Excel software.

Inhibition $(\%)=\left[1-\left(\mathrm{S}-\mathrm{S}_{0}\right) /\left(\mathrm{C}-\mathrm{C}_{0}\right)\right] \times 100$

Where $C$ is the fluorescence of the control (enzyme and substrate) after $30 \mathrm{~min}$ of incubation, $\mathrm{C}_{0}$ is the fluorescence of the control at zero time, $\mathrm{S}$ is the fluorescence of the tested samples (enzyme, sample, and substrate) after incubation, and $\mathrm{S}_{0}$ is the fluorescence of the tested samples at zero time.

\section{Virus and cell culture}

The influenza A virus was provided by ATCC (American Type Culture Collection) and propagated in MDCK cells at $37^{\circ} \mathrm{C}$. MDCK cells were maintained in minimal essential medium (MEM) supplemented with $10 \%$ fetal bovine serum (FBS) and $0.01 \%$ antibiotic-antimycotic solution. Antibiotic-antimycotic solution, trypsin-EDTA, FBS, and MEM were purchased from Gibco BRL. Tissue culture plates were purchased from Falcon. SRB and zanamivir (purity of $>98 \%$ ) were purchased from Sigma-Aldrich. 


\section{Assays of antiviral activity and cytotoxicity}

Antiviral activity and cytotoxicity were evaluated by the SRB method, which involves assessing the degree of reduction in the CPE [15]. Briefly, MDCK cells were seeded in 96-well culture plates at a concentration of $2 \times 10^{4}$ cells/well. The cells were then incubated for $18-24 \mathrm{~h}$ at $37^{\circ} \mathrm{C}$, after which the medium was removed and the cells were washed with PBS. After washing, $0.09 \mathrm{~mL}$ of diluted virus suspension and $0.01 \mathrm{~mL}$ of medium supplemented with trypsin-EDTA and compounds 1-7 or zanamivir, the positive control, were added in 10 -fold dilutions ranging from 0.1 to $100 \mu \mathrm{M}$. Cells were incubated at $37^{\circ} \mathrm{C}$ in $5 \% \mathrm{CO}_{2}$ for two days. After washing once with $\mathrm{PBS}, 100 \mu \mathrm{L}$ of cold $\left(-20^{\circ} \mathrm{C}\right)$ $70 \%$ acetone were added to each well, and the cells were fixed for $30 \mathrm{~min}$ at $-20^{\circ} \mathrm{C}$. The acetone was then removed, and the 96well plates were dried in an oven for $30 \mathrm{~min}$. After drying, $100 \mu \mathrm{L}$ of $0.4 \%(\mathrm{w} / \mathrm{v})$ SRB in $1 \%$ acetic acid solution were added to each well, followed by incubation for $30 \mathrm{~min}$ at room temperature. Unbound SRB was then removed, and the plates were washed five times with $1 \%$ acetic acid. Plates were then placed in a drying oven for $24 \mathrm{~h}$. Bound SRB was solubilized with $100 \mu \mathrm{L}$ of $10 \mathrm{mM}$ unbuffered Tris-base solution, and the plates were incubated for $30 \mathrm{~min}$. The resulting absorbance at $540 \mathrm{~nm}$ was obtained using a VERSAmax microplate reader, with the reference absorbance set to $620 \mathrm{~nm}$. Zanamivir was used as a positive control in the CPE inhibition test.

The morphology was assessed using a light microscope at $20 \times 10$ magnification. Images were recorded with Leica Application Suite V2.7 software. The $50 \%$ inhibitory concentration $\left(\mathrm{IC}_{50}\right)$ and $50 \%$ cytotoxic concentration $\left(\mathrm{CC}_{50}\right)$ were calculated by regression analysis.

\section{Supporting information}

NMR assignments of compounds $\mathbf{1 - 7}$ are available as Supporting Information.

\section{Acknowledgements \\ $\nabla$}

We thank emeritus professor Kwang-Ryul Choi (Chungnam National University) for support and identification of the bee pollen material. This work was supported by a grant from the Basic Research Program through the National Research Foundation of Korea (NRF), funded by the Ministry of Science, ICT \& Future Planning (2012R1A1A3011559). This research was supported by "Research Base Construction Fund Support Program" funded by Chonbuk National University in 2015.

\section{Conflict of Interest}

\section{$\nabla$}

The authors declare no conflict of interest.

\section{References}

1 Graikou K, Kapeta S, Aligiannis N, Sotiroudis G, Chondrogianni N, Gonos E, Chinou I. Chemical analysis of Greek pollen - antioxidant, antimicrobial and proteasome activation properties. Chem Cent J 2011; 5: 33-41

2 Morais M, Moreira L, Feás X, Estevinho LM. Honeybee-collected pollen from five Portuguese natural parks: palynological origin, phenolic content, antioxidant properties and antimicrobial activity. Food Chem Toxicol 2011; 49: 1096-1101

3 Maruyama H, Sakamoto T, Araki Y, Hara H. Anti-inflammatory effect of bee pollen ethanol extract from Cistus sp. of Spanish on carrageenaninduced rat hind paw edema. BMC Complement Altern Med 2010; 10: 30-41

4 Medeiros KC, Figueiredo CA, Figueredo TB, Freire KR, Santos FA, Alcantara-Neves NM, Silva TM, Piuvezam MR. Anti-allergic effect of bee pollen phenolic extract and myricetin in ovalbumin-sensitized mice. J Ethnopharmacol 2008; 119: 41-46

5 Ozcan M. Inhibition of Aspergillus parasiticus NRRL 2999 by pollen and propolis extracts. J Med Food 2004; 7: 114-116

6 Furusawa E, Chou SC, Hirazumi A, Melera A. Antitumour potential of pollen extract on lewis lung carcinoma implanted intraperitoneally in syngeneic mice. Phytother Res 1995; 9: 255-259

7 Pinto B, Cagiagli F, Riccio E, Reali D, Saric A, Balog T, Likic S, Scarpato R. Antiestrogenic and antigenotoxic activity of bee pollen from Cystus incanus and Salix alba as evaluated by the yeast estrogen screen and the micronucleus assay in human lymphocytes. Eur J Med Chem 2010; 45: $4122-4128$

8 Pascoal A, Rodrigues S, Teixeira A, Feas X, Estevinho LM. Biological activities of commercial bee pollens: antimicrobial, antimutagenic, antioxidant and anti-inflammatory. Food Chem Toxicol 2014; 63: 233-239

9 Negri G, Teixeira EW, Alves ML, Moreti AC, Otsuk IP, Borguini RG, Salatino A. Hydroxycinnamic acid amide derivatives, phenolic compounds and antioxidant activities of extracts of pollen samples from Southeast Brazil. J Agric Food Chem 2011; 59: 5516-5522

10 Grienke U, Schmidtke M, Grafenstein SV, Kirchmair J, Liedl KR, Rollinger $J M$. Influenza neuraminidase: a druggable target for natural products. Nat Prod Rep 2012; 29: 11-36

11 Hillenbrand M, Zapp J, Becker H. Depsides from the petals of Papaver rhoeas. Planta Med 2004; 70: 380-382

12 Niu XF, Xu HB, Liu X, Fan T, Qi L. Isoquinoline alkaloids from Corydalis impatiens. Chem Nat Compd 2013; 49: 187-189

13 Wynne PM, Vine JH, Amiet RG. Protopine alkaloids in horse urine. J Chromatogr B Analyt Technol Biomed Life Sci 2004; 811: 85-91

14 Ryu YB, Kim JH, Park SJ, Chang JS, Rho MC, Bae KH, Park KH, Lee WS. Inhibition of neuraminidase activity by polyphenol compounds isolated from the roots of Glycyrrhiza uralensis. Bioorg Med Chem Lett 2010; 20: 971-974

15 Choi HJ, Song JH, Park KS, Kwon DH. Inhibitory effects of quercetin 3rhamnoside on influenza A virus replication. Eur J Pharm Sci 2009; 37: $329-333$ 